Антитромботическая терапия и ее влияние на прогноз у больных с фибрилляцией предсердий, перенесших инфаркт миокарда. Данные многолетнего наблюдения

\author{
М.В. Соловьева ${ }^{\boxplus}$, С. Болдуева \\ ФГБоу ВО «Северо-Западный государственный медицинский университет им. И.И. Мечникова» Минздрава России, Санкт-Петербург, Россия
}

\begin{abstract}
Аннотация
Цель. Изучить особенности антитромботической терапии (АТТ) у пациентов с инфарктом миокарда (ИМ) 1-го типа и предсуществующей фибрилляцией предсердий (ФП), влияние АТТ на прогноз.

Материал и методы. Из 1660 пациентов с ИМ отобраны 100 с ИМ 1-го типа и предсуществующей ФП. Критерий исключения - тяжелая сопутствующая патология.

Результаты. До госпитализации лишь 13,0\% пациентов с ФП принимали антикоагулянты (АК) адекватно. Большинству пациентов в стационаре (94,0\%) и при выписке (80,5\%) назначена тройная АТТ минимально на 1 мес с переходом на двойную (АК + 1 дезагрегант), как правило, на 12 мес. АК назначались в стационаре в 100,0\% случаев, при выписке - в 93,1\%. Чаще использовались прямые оральные АК

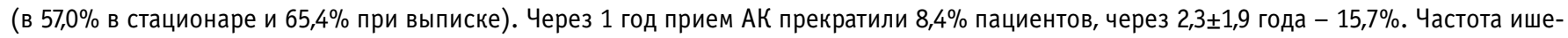
мических и геморрагических событий в зависимости от объема терапии (двойная/тройная) и типа АК (антагонисты витамина К/прямые оральные АК) при адекватном приеме в отдаленном периоде не отличалась. Некорректный прием или отмена АК в отдаленном периоде увеличили риски инсульта (отношение шансов 9,580; $95 \%$ доверительный интервал 1,153-79,599, $p=0,0365$ ); комбинированной конечной точки: повторный ИМ + инсульт + сердечно-сосудистая смертность (отношение шансов 2,556; 95\% доверительный интервал 1,104-5,918, $p=0,0284)$.

Заключение. У пациентов с предсуществующей ФП наблюдалась низкая приверженность приему АК в прединфарктный период, после госпитализации по поводу ИМ она повышалась, в процессе наблюдения снижалась. Некорректный прием или отмена АК достоверно повышали риски инсульта, комбинированной конечной точки. Различий в прогнозе в зависимости от вида АК, объема ATT при назначении в соответствии с ишемическими и геморрагическими рисками не отмечено.
\end{abstract}

Ключевые слова: фибрилляция предсердий, инфаркт миокарда, антитромботическая терапия, антикоагулянты, прогноз, приверженность приему антикоагулянтов

Для цитирования: Соловьева М.В., Болдуева С.А. Антитромботическая терапия и ее влияние на прогноз у больных с фибрилляцией предсердий, перенесших инфаркт миокарда. Данные многолетнего наблюдения. CardioСоматика. 2021; 12 (3): 158-165.

DOI: $10.26442 / 22217185.2021 .3 .201044$

\title{
Antithrombotic therapy and its impact on prognosis in patients with atrial fibrillation and myocardial infarction. Long-term observation results
}

\section{Mariia V. Soloveva ${ }^{\bowtie}$, Svetlana A. Boldueva \\ Mechnikov North-Western State Medical University, Saint Petersburg, Russia}

\section{Abstract}

Aim. To study antithrombotic therapy (ATT) in patients with myocardial infarction (MI) type 1 and preexisting atrial fibrillation (AF), effect of ATT on prognosis.

Material and methods. 100 patients with type 1 MI and preexisting AF were selected. The exclusion criterion was severe concomitant pathology.

Results. Only $13.0 \%$ of AF patients took anticoagulants (AC) adequately before hospitalization. $94.0 \%$ of patients in hospital and $80.5 \%$ at discharge were prescribed triple ATT atleast for 1 month with transition to dual ATT (AC + disaggregant) for 12 months. ACs were prescribed

\section{СПИСОК СОКРАЩЕНИЙ}

АВК - антагонист витамина К

АК - антикоагулянты

АСК - ацетилсалициловая кислота

АТТ - антитромботическая терапия

ДААТ - двойная антиагрегантная терапия

ИМ - инфаркт миокарда
ККТ - комбинированная конечная точка

МНО - международное нормализованное отношение

ПОАК - прямые оральные антикоагулянты

ТЭЛА - тромбоэмболия легочной артерии

ФП - фибрилляция предсердий

ЧКВ - чрескожное коронарное вмешательство 
in hospital in $100.0 \%$ of cases, at discharge - in $93.1 \%$. After 1 year $8.4 \%$ of patients stopped taking ACs, after $2.3 \pm 1.9$ years $-15.7 \%$. The incidence of ischemic and hemorrhagic events didn't differ in patients with different regimens of ATT (double/triple) and types of ACs (vitamin $\mathrm{K}$ antagonists/non-vitamin $\mathrm{K}$ antagonist $\mathrm{ACs}$ ). In thelong-term period patients, who took ACs incorrectly or stopped taking $\mathrm{ACs}$, had increased risks of stroke (OR 9.580; 95\% CI 1.153-79.599, $p=0.0365)$; combined endpoint: recurrent MI + stroke + cardiovascular mortality (OR 2.556; 95\% CI 1.104-5.918, $p=0.0284$ ).

Conclusion. Patients with preexisting AF had alow adherence to ACs prior to MI. It increased after hospitalization and decreased during follow-up. In thelong-term period patients, who took ACs incorrectly or stopped taking ACs, had significantly increased risks of stroke, combined endpoint. There were no differences in the prognosis depending on the type of ACs, the regimens of ATT administered in accordance with ischemic and hemorrhagic risks.

Keywords: atrial fibrillation, myocardial infarction, antithrombotic therapy, anticoagulants, prognosis, adherence to anticoagulants For citation: Soloveva MV, Boldueva SA. Antithrombotic therapy and its impact on prognosis in patients with atrial fibrillation and myocardial infarction. Long-term observation results. Cardiosomatics. 2021; 12 (3): 158-165. DOI: 10.26442/22217185.2021.3.201044

\section{Введение}

Фибрилляция предсердий (ФП) - общеизвестный фактор риска тромбоэмболических событий. При рассмотрении вопроса антитромботической терапии (АТТ) у лиц с ФП обычно основное внимание уделяется профилактике инсультов. Однако в последнее время стали появляться научные исследования, доказывающие, что ФП также увеличивает риски развития инфаркта миокарда (ИМ) и при отсутствии адекватной АТТ способствует ухудшению прогноза у пациентов, перенесших ИМ [1-3]. Рост продолжительности жизни населения и постоянное увеличение числа пациентов с ФП делают проблему АТТ у данной категории больных с каждым годом все более актуальной.

Цель исследования - изучение особенностей АТТ и ее влияния на внутригоспитальный и отдаленный прогноз у пациентов с ИМ 1-го типа и предсуществующей ФП.

\section{Материал и методы}

В период с 2013 по 2018 г. в кардиологическое отделение ФГБОУ ВО «СЗГМУ им. И.И. Мечникова» поступили 1660 больных с ИМ. Из числа этих пациентов последовательно отобрана группа больных с сочетанием ИМ и всех форм ФП, всего 309 человек (18,6\% от всех больных с ИМ). Принимая во внимание тот факт, что не у всех пациентов с выявленной ФП можно было точно оценить время появления ФП (впервые зарегистрированная ФП или ФП, впервые возникшая в остром периоде ИМ), в исследование включались только пациенты с предсуществующей ФП, которая верифицирована до ИМ по данным медицинской документации. Число больных с ИМ и предсуществующей ФП составило 183 человека (59,2\% от больных с ИМ и всеми формами ФП). Из этих пациентов сформирована группа исследования - больные с ИМ 1-го типа и предсуществующей ФП, не имевшие тяжелой сопутствующей патологии, способной повлиять на прогноз; всего - 100 человек.

Протокол исследования одобрен локальным этическим комитетом. Все пациенты дали информированное согласие на участие в исследовании.

В ходе стационарного лечения обследование больных выполнялось по стандартному протоколу согласно рекомендациям по ведению пациентов с ИМ $[4,5]$. Время наблюдения за пациентами составило в среднем $2,3 \pm 1,9$ года (максимально - 7,2 года). После выписки больных из стационара проводились очные осмотры 1 раз в 12 мес, при их невозможности - телефонные опросы. Судьба 4 пациентов осталась неизвестной, так как они не приходили на визиты, не отвечали на звонки. Эти больные исключены из анализа отдаленного прогноза.

Задачами исследования явились: изучение характера АТТ до ИМ, в период стационарного лечения и после выписки, а также оценка влияния АТТ на прогноз. Сравнивались все варианты АТТ, принимаемой в стационаре и в отдаленном периоде (через 1 год после ИМ и к моменту финального визита) между собой, а также отдельно - антагонист витамина К (АВК) и прямые оральные антикоагулянты (ПОАК) в составе АТТ. Кроме того, проводилось сравнение прогноза заболевания у тех пациентов, кто адекватно принимал антикоагулянты (АК) с теми, кто после выписки или не получал АК или использовал их нерегулярно и в некорректных дозах. Как во время госпитализации, так и в отдаленном периоде изучались следующие конечные точки: рецидив ИМ/повторный ИМ (через 30 дней после выписки), инсульт, тромбоэмболия легочной артерии (ТЭЛА), большие и малые кровотечения, общая и сердечно-сосудистая смертность, комбинированная конечная точка - ККТ (рецидив/ повторный ИМ + инсульт + сердечно-сосудистая смертность). В стационаре все случаи смерти имели кардиальный генез, в связи с чем внутригоспитальная конечная точка обозначена как «смертность», без деления ее на общую и сердечнососудистую.

Статистическая обработка данных проводилась в программе SAS (SAS Institutes Inc., США). Для сравнения внутригоспитального прогноза в зависимости от схемы АТТ использован $\chi^{2}$, внегоспитального прогноза - модель пропорциональных рисков Кокса с оценкой времени до наступления конечных точек, без учета повторных событий.

\section{Результаты}

\section{Характеристика группы исследования}

Давность ФП к моменту госпитализации в связи с ИМ у больных составляла от 0,5 до 252 мес: Me 52 мес (IQR 680 мес). Постоянная форма ФП имела место у 49 (49,0\%) пациентов, пароксизмальная - у 40 (40,0\%), персистирующая - у 11 (11,0\%).

Характеристика пациентов представлена в табл. 1.

Для большинства пациентов в исследуемой группе характерен отягощенный анамнез. Больные имели сниженную скорость клубочковой фильтрации, нарушение липидного обмена. Риск тромбоэмболических осложнений у них преобладал над риском кровотечений $(p<0,001)$. Высокий риск по шкале CHA2DS2-VASc имел место у 97,0\% пациентов, высокий риск по шкале HAS-BLED - у 63,0\%.

В большинстве случаев зарегистрирован ИМ с подъемом $S T$, чаще переднебоковой. Средние значения фракции выброса на фоне ИМ умеренно сниженные или сохранные. У пациентов преобладали проксимальные стенозы коронарных артерий. В ходе госпитализации реваскуляризация инфарктсвязанной артерии выполнена в 82,0\% случаев, чаще (в 56,0\%) в течение 6 ч от начала болевого синдрома. Чрескожное коронарное вмешательство (ЧКВ) не проводилось 18,0\% больных в связи со сроками ИМ к моменту госпитализации, отказом больных.

\section{ATT на догоспитальном этапе и ее влияние на госпи-} тальный прогноз

В группе исследования до госпитализации и в связи с ИМ лишь 13,0\% пациентов принимали АК правильно. Остальные 
Таблица 1. Характеристика пациентов в исследуемой группе

Table 1. Patient characteristics in the study group

\begin{tabular}{|c|c|}
\hline Признак & Значение \\
\hline Женщины, абс. [\%] & $58(58,0)$ \\
\hline Средний возраст, $\mathrm{M} \pm \mathrm{SD}$, лет & $75,5 \pm 8,7$ \\
\hline Индекс массы тела, $\mathrm{M} \pm \mathrm{SD}, \mathrm{kr} / \mathrm{M}^{2}$ & $27,8 \pm 5,5$ \\
\hline Курение, абс. (\%) & $28(28,0)$ \\
\hline Сахарный диабет, абс. (\%) & $45(45,0)$ \\
\hline Гипертоническая болезнь, абс. (\%) & $98(98,0)$ \\
\hline $\begin{array}{l}\text { Ишемическая болезнь сердца в анамнезе, } \\
\text { абс. }(\%)\end{array}$ & $72(72,0)$ \\
\hline Постинфарктный кардиосклероз, абс. (\%) & $40(40,0)$ \\
\hline Инсульт в анамнезе, абс. (\%) & $21(21,0)$ \\
\hline 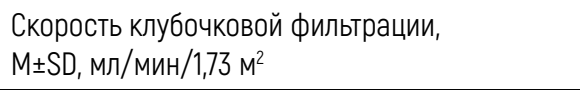 & $56,8 \pm 19,4$ \\
\hline Общий холестерин, $\mathrm{M} \pm \mathrm{SD}$, ммоль/л & $4,6 \pm 1,1$ \\
\hline $\begin{array}{l}\text { Липопротеиды низкой плотности, } \mathrm{M} \pm \mathrm{SD} \text {, } \\
\text { ммоль/л }\end{array}$ & $2,8 \pm 0,9$ \\
\hline CHA2DS2-VASc, M $\pm S D$, баллы & $4,6 \pm 1,9$ \\
\hline HAS-BLED, M $\pm S D$, баллы & $1,7 \pm 0,9$ \\
\hline $\begin{array}{l}\text { Тропонин (максимальные значения), } \\
\mathrm{M} \pm \mathrm{SD} / \mathrm{Me} \pm I Q R, \text { пг/мл }\end{array}$ & $\begin{array}{c}2272,3(2735,0) / 1030,1 \\
(2856,3)\end{array}$ \\
\hline ИМ с подъемом ST, абс. (\%) & $62(62,0)$ \\
\hline Фракция выброса, MะSD, \% & $55,2 \pm 10,5$ \\
\hline \multicolumn{2}{|l|}{ Локализация ИМ } \\
\hline Переднебоковой, абс. (\%) & $48(48,0)$ \\
\hline Нижнезадний, абс. (\%) & $17(17,0)$ \\
\hline Нижнебоковой, абс. (\%) & $17(17,0)$ \\
\hline Передний, абс. (\%) & $12(12,0)$ \\
\hline Циркулярный, абс. (\%) & $3(3,0)$ \\
\hline $\begin{array}{l}\text { Нижнебоковой и нижнезадний с захватом } \\
\text { правого желудочка, абс. }[\%]\end{array}$ & $3(3,0)$ \\
\hline
\end{tabular}

Гемодинамически значимые нарушения ритма

\begin{tabular}{|l|c|}
\hline $\begin{array}{l}\text { Атриовентрикулярная блокада 3-й степени, } \\
\text { абс. }(\%)\end{array}$ & $6(6,0)$ \\
\hline Устойчивая желудочковая тахикардия, абс. $(\%)$ & $1(1,0)$ \\
\hline Фибрилляция желудочков, абс. $(\%)$ & $5(5,0)$ \\
\hline \multicolumn{2}{|c|}{ Поражение коронарных артерий } \\
\hline Однососудистое, абс. (\%) & $31(31,0)$ \\
\hline Двусосудистое, абс. (\%) & $39(39,0)$ \\
\hline Трехсосудистое, абс. (\%) & $30(30,0)$ \\
\hline Проксимальное, абс. (\%) & $69(69,0)$ \\
\hline Дистальное, абс. (\%) & $3(3,0)$ \\
\hline Проксимальное + дистальное, абс. (\%) & $28(28,0)$ \\
\hline
\end{tabular}

больные либо не принимали АК вообще (в 70,1\% случаев), либо получали их нерегулярно (3,9\%) и в некорректных дозах $(13,0 \%)$. Интересно, что наибольшая доля пациентов, не принимавших или неадекватно использовавших АК до госпитализации, чаще встречалась в период 2014-2015 гг. (100,0\% больных), чем в 2018 г. (68,75\%).

Следует отметить, что все пациенты, кто перенес ТЭЛА в первые 2 сут от ИМ (9 человек), либо не получали АК до госпитализации, либо принимали их неправильно, 1 из 2 пациентов с кардиоэмболическим инсультом, развившимся в 1-е сутки ИМ, также ранее АК не принимал. Среди умерших в стационаре пациентов с известной до госпитализации терапией у 10 из 11 человек АК в составе терапии отсутствовали.

\section{ATт на госпитальном этапе}

Состав АТТ у пациентов в группе исследования в ходе стационарного лечения представлен в табл. 2.

В состав АТТ всегда входили АК и в 99,0\% случаев - дезагреганты. Дезагреганты не назначены лишь 1 пациентке, поступившей в стационар в крайне тяжелом состоянии, с кардиогенным шоком, исходной тяжелой анемией, и умершей менее чем через 1 ч после госпитализации. Ей выполнена только ангиопластика инфарктсвязанной артерии, и она получала гепарин внутривенно.

Таким образом, в 94,0\% случаев на госпитальном этапе пациенты получали тройную АТТ, причем в качестве АК в ее составе чаще всего применялись ПОАК: в 55,0\% случаев по сравнению с 29,0 и 10,0\% назначений АВК и парентеральных АК соответственно. Из тех пациентов, кто получал тройную терапию, 9,6\% принимали ее только в ходе госпитализации, то есть в течение 7-10 дней, с дальнейшим переходом при выписке на двойную терапию; остальным 90,4\% больных рекомендовано продолжить тройную терапию в течение 3-6 мес в зависимости от соотношения ишемических и геморрагических рисков. В составе тройной терапии в 94,7\% случаев использованы ацетилсалициловая кислота (АСК) в дозе 75-100 мг и клопидогрел, зна-

Таблица 2. АТТ в исследуемой группе на госпитальном этапе (n=100) Table 2. Antithrombotic therapy (ATT) in the study group at the hospital stage $(n=100)$

\begin{tabular}{|c|c|}
\hline Схема АТT & $\begin{array}{c}\text { Группа } \\
\text { исследования, } \\
\text { абс. }(\%)\end{array}$ \\
\hline 1 АК (парентеральный) & $1(1,0)$ \\
\hline \multicolumn{2}{|l|}{ Двойная АТТ } \\
\hline Клопидогрел + АВК & $1(1,0)$ \\
\hline Клопидогрел + ПОАК & $2(2,0)$ \\
\hline Тикагрелор 180 мг/сут + парентеральный АК & $2(2,0)$ \\
\hline \multicolumn{2}{|l|}{ Тройная АТТ (ДААТ+АВК) } \\
\hline АСК 75-100 мг + клопидогрел + АВК & $27(27,0)$ \\
\hline АСК 75-100 мг + тикагрелор + АВК & $2(2,0)$ \\
\hline \multicolumn{2}{|c|}{ Тройная антитромботическая (ДААТ+ПОАК) } \\
\hline АСК 75-100 мг + клопидогрел + ПОАК & $53(53,0)$ \\
\hline АСК 75-100 мг + тикагрелор + ПОАК & $2(2,0)$ \\
\hline \multicolumn{2}{|c|}{$\begin{array}{l}\text { Тройная антитромботическая } \\
\text { (ДААТ + парентеральный АК) }\end{array}$} \\
\hline $\begin{array}{l}\text { АСК 75-100 мг + клопидогрел + } \\
\text { парентеральный АК }\end{array}$ & $9(9,0)$ \\
\hline $\begin{array}{l}\text { АСК } 100 \text { мг + тикагрелор } 180 \text { мг/сут + } \\
\text { парентеральный АК }\end{array}$ & $1(1,0)$ \\
\hline
\end{tabular}


чительно реже (5,3\%) - АСК 100 мг и тикагрелор. Тикагрелор назначался тем пациентам, у кого ранее в анамнезе имел место тромбоз стента на фоне приема двойной антиагрегантной терапии (ДААТ) с клопидогрелом, или если при исследовании агрегации тромбоцитов (verifynow) доказана неэффективность клопидогрела.

Двойную АТТ получали 5 (5,0\%) пациентов, у 1 из них применялся АВК, у 2 - ПОАК, у 2 - парентеральные АК. Все больные, получавшие двойную терапию в ходе госпитализации, переносили ИМ без подъема ST и имели высокий риск кровотечений по шкале HAS-BLED (3 балла и более), значительно преобладающий над риском тромбоэмболических событий по шкале CHA2DS2-VASc (2 балла), а также - низкий риск тромбоза стента. В качестве дезагрегантов в составе двойной терапии всегда использовался блокатор Р2Ү12-рецепторов: в 3 случаях клопидогрел, в 2 - тикагрелор.

В качестве АК 13 пациентов получали только парентеральные АК, из них 9 (69,2\%) больных - гепарин внутривенно, 4 (30,8\%) - низкомолекулярные гепарины подкожно (эноксапарин, далтепарин). В 10 из 13 случаев парентеральные АК назначены в составе тройной АТТ, в 2 случаях - в составе двойной АТТ (в комбинации с тикагрелором), у 1 пациента по изложенным причинам использован только гепарин внутривенно.

\section{Влияние АТт на внутригоспитальный прогноз}

Учитывая малое количество событий и больных в группах с различными вариантами ATT, оценить ее влияние на возникновение внутригоспитальных конечных точек (рецидива ИМ, инсульта, ТЭЛА, смертности, ККТ) не представлялось возможным. Но обращала на себя внимание группа пациентов (13 человек), которые в качестве АК получали только парентеральные формы. Все эти больные умерли в отделении реанимации и интенсивной терапии: в 9 случаях в течение первых суток, в остальных - в сроки от 2 до 4 сут. Следует отметить, что данные пациенты исходно поступили в тяжелом состоянии, 10 из 13 пациентов - в крайне тяжелом (с кардиогенным шоком), все имели многососудистое или стволовое поражение коронарных артерий, были пожилого или старческого возраста, что, безусловно, оказывало значимое влияние на прогноз. Причинами смерти в 53,8\% случаях стала асистолия, в $23,1 \%$ - разрыв миокарда, в 15,4\% - фибрилляция желудочков, в 7,7\% - ТЭЛА.

Среди пациентов с другими вариантами АТТ умерших в ходе госпитализации пациентов не отмечено.

Таблица 3. Сравнение АВК и ПОАК в составе тройной АТТ по влиянию на внутригоспитальные события

Table 3. Comparison of vitamin K antagonists (VKA) and direct oral anticoagulants (DOACs) in the triple ATT by their effect on in-hospital events

\begin{tabular}{|l|c|c|c|}
\hline \multirow{2}{*}{$\begin{array}{c}\text { Внутри- } \\
\text { госпитальное } \\
\text { событие }\end{array}$} & ДААТ+АВK & ДААТ+ПОАК & $\begin{array}{c}\text { Значимость } \\
\text { различий } \boldsymbol{p}\end{array}$ \\
\cline { 2 - 4 } Рецидив ИМ & $0 / 29(0,0)$ & $0 / 55(0,0)$ & 1,000 \\
\hline Инсульт & $0 / 29(0,0)$ & $1 / 55(2,9)$ & 0,4651 \\
\hline ТЭЛА & $1 / 29(4,8)$ & $2 / 55(5,7)$ & 0,9648 \\
\hline $\begin{array}{l}\text { Большие } \\
\text { кровотечения }\end{array}$ & $1 / 29(3,4)$ & $0 / 55(0,0)$ & 0,3452 \\
\hline $\begin{array}{l}\text { Малые } \\
\text { кровотечения }\end{array}$ & $3 / 29(10,3)$ & $12 / 55(21,8)$ & 0,5806 \\
\hline Смертность & $0 / 29(0,0)$ & $0 / 55(0,0)$ & 1,000 \\
\hline ККТ & $0 / 29(0,0)$ & $1 / 55(1,8)$ & 0,4651 \\
\hline
\end{tabular}

Частота кровотечений в стационаре не зависела от схемы ATT ( $p=0,45$ для больших кровотечений, $p=0,24$ для малых). Единственное большое кровотечение зарегистрировано на фоне приема тройной АТТ и являлось постпункционной (после ЧКВ) гематомой плеча. Большинство $(71,4 \%)$ малых кровотечений также произошло на фоне тройной АТТ. В 57,0\% случаев малое кровотечение являлось микрогематурией, реже - макрогематурией и желудочно-кишечным кровотечением (по 14,3\%), носовым кровотечением и постпункционной (после ЧКВ) гематомой плеча или бедра (по 4,8\%).

В связи с малым числом пациентов, получавших двойную ATT с оральным АК в ее составе (3 человека), сравнение ее с тройной терапией по влиянию на внутригоспитальные конечные точки не выполнялось.

Достоверных различий по наступлению в ходе госпитализации изучаемых событий, ККТ в зависимости от АК, входящего в состав наиболее распространенной тройной АТТ, не получено (табл. 3).

\section{ATT в отдаленном периоде}

Тройная АТТ при выписке согласно существующим в тот период времени рекомендациям назначена 80,5\% больных: из них в 78,6\% случаев - на 1 мес, реже - в 5,7\% на 3 мес и в 15,7\% на 6 мес, с дальнейшим переходом на двойную терапию (1 дезагрегант в сочетании с АК) на 12 мес в 95,7\% случаев. Двойная АТТ при выписке назначена 12,6\% больных: чаще (81,8\% случаев) на 12 мес. Продолжительность приема дезагрегантов (как АСК, так и блокаторов Р2Y12) в составе двойной и тройной АТТ рекомендовано сократить в 5,6\% случаев до 1-6 мес с переходом на прием только АК в связи с высоким риском или рецидивирующими кровотечениями во время стационарного лечения. Таким образом, срок приема дезагрегантов подбирался индивидуально и зависел от соотношения риска ишемических событий и риска кровотечений.

В состав АТТ в 93,1\% случаев при выписке входили АК, среди которых преобладали ПОАК (65,4\%), АВК назначен 34,6\% больных. Среди ПОАК наиболее часто назначался апиксабан (в 54,7\% случаев по сравнению с $32,1 \%$ для ривароксабана и 13,2\% для дабигатрана). АК всем пациентам назначены для постоянного приема с регулярным амбулаторным контролем международного нормализованного отношения - МНО (при назначении АВК) и почечной функции (при ПОАК).

АК не назначены 6 (6,9\%) пациентам в 2014-2016 гг.: по социальным причинам (невозможность приема варфарина в связи с отсутствием адекватного контроля МН0, недоступность ПОАК в связи с их ценой). Этим пациентам назначена ДААТ с АСК и блокатором Р2Ү12 (в 4 случаях - тикагрелором и в 2 - клопидогрелом).

Схемы АТТ рекомендовано корректировать в зависимости от клинической ситуации (сердечно-сосудистых событий, кровотечений) в ходе регулярных приемов кардиолога по месту жительства. Всем пациентам при выписке назначены ингибиторы протонной помпы.

В ходе визита через 1 год оценен состав АТT, которую больные принимали в течение 1 года после выписки (табл. 4).

Тройную АТТ получали 77,9\% пациентов: из них в течение 1 мес в 77,4\% случаев, в течение 3-6 мес - в 22,6\%. Блокатор Р2Y12-рецепторов чаще всего больные принимали в течение 12 мес. Только в 1 случае в связи с большим желудочно-кишечным кровотечением ДААТ в составе АТТ прекращена через 1 мес, с переходом сразу только на один АК. Амбулаторно АСК чаще, чем во время госпитализации (19,5\% против 5,0\% соответственно, $p=0,0031$ ), использовалась в меньшей дозе (75 мг, а не 100 мг). В качестве блокатора Р2Ү12-рецепторов в составе тройной АТТ всегда применялся клопидогрел. 
Таблица 4. АТТ в течение 1 года после выписки $(\mathrm{n}=68)^{*}$

Table 4. ATT within 1 year after discharge $(n=68)^{*}$

\begin{tabular}{|l|c|}
\hline \multicolumn{1}{|c|}{ Схема АТТ } & $\begin{array}{c}\text { Группа исследования, } \\
\text { абс. (\%) }\end{array}$ \\
\hline \multicolumn{2}{|c|}{ Двойная АТТ (1 дезагрегант + АВK) } \\
\hline Клопидогрел 1 мес + АВК & $2(2,9)$ \\
\hline Клопидогрел 12 мес + АВК & $1(1,5)$ \\
\hline
\end{tabular}

\begin{tabular}{|c|c|}
\hline \multicolumn{2}{|c|}{ Двойная АТТ (1 дезагрегант + ПОАК) } \\
\hline Клопидогрел 3 мес + ПОАК & $1(1,5)$ \\
\hline Клопидогрел 12 мес + ПОАК & $7(10,3)$ \\
\hline \multicolumn{2}{|l|}{ Тройная АТТ (ДААТ+АВК) } \\
\hline АСК 100 мг 1 мес + клопидогрел 1 мес + АВК & $1(1,5)$ \\
\hline $\begin{array}{l}\text { АСК 75-100 мг } 1 \text { мес + клопидогрел } 12 \text { мес + } \\
\text { АВК }\end{array}$ & $13(19,1)$ \\
\hline $\begin{array}{l}\text { АСК 75-100 мг 3-6 мес + клопидогрел } 12 \text { мес + } \\
\text { АВК }\end{array}$ & $5(7,3)$ \\
\hline
\end{tabular}

\begin{tabular}{|l|c|}
\hline \multicolumn{2}{|c|}{ Тройная АТТ (ДААТ+ПОАК) } \\
\hline $\begin{array}{l}\text { АСК 75-100 мг 1 мес + клопидогрел 12 мес + } \\
\text { ПОАК }\end{array}$ & $27(39,7)$ \\
\hline $\begin{array}{l}\text { АСК 75-100 мг 3-6 мес + клопидогрел 12 мес + } \\
\text { ПОАК }\end{array}$ & $7(10,3)$ \\
\hline \multicolumn{2}{|c|}{ ДААТ } \\
\hline АСК 75-100 мг + тикагрелор 12 мес & $3(4,4)$ \\
\hline АСК 75-100 мг + клопидогрел 12 мес & $1(1,5)$ \\
\hline
\end{tabular}

*Из числа пациентов исключены те, кто умер в ходе госпитализации (13 пациентов), в течение 1 года после госпитализации (10 больных), а также те пациенты, кто не выходил на связь вообще (4 человека) или выбыл из исследования ранее 1 года (5 пациентов).

Двойную АТТ (с клопидогрелом и АК в составе) принимали 11 пациентов (16,2\% случаев), чаще (в 8 из 12 случаев) - в течение 12 мес, реже (в 3 случаях) - 1-3 мес. ДААТ получали 5,9\% пациентов.

В составе и двойной, и тройной АТТ после выписки, так же как и в стационаре, в качестве АК больные чаще принимали ПОАК (65,6\%), всегда в сниженных дозах, с дальнейшим переходом на полные дозы после отмены дезагрегантов. В течение 1 года АК отменили 8,4\% пациентов. В некорректных дозах или нерегулярно принимали АК 9,6\% больных. Таким образом, приверженность антикоагулянтной терапии при оценке через 1 год после выписки составила 82,0\%.

К моменту финального визита - M (SD) $=2,3 \pm 1,9$ года, максимально 7,3 года после перенесенного ИМ - АК продолжили принимать 84,3\% пациентов, из них неадекватный прием АК наблюдался у 21,6\% пациентов. Таким образом, приверженность антикоагулянтной терапии к моменту финального визита составила 62,7\%. Среди АК преобладали ПОАК (72,9\% назначений). Большинство (41,4\%) пациентов принимали апиксабан, наименьшая (5,7\%) доля больных - дабигатран, ривароксабан присутствовал в схеме лечения у 25,7\% пациентов. Прием АК прекращен в 15,7\% случаев (13 больных). Отмена АК в 2 случаях связана с кровотечениями (на фоне приема АВК и ривароксабана), при этом прием АК в дальнейшем не возобновлялся. В 11 случаях объяснениями причины отказа лечения АК стали невозможность приема АВК в связи с трудностями контроля МНО и недоступность ПОАК в связи с их ценой.
Таблица 5. Прием варфарина и ПОАК после выписки из стационара к моменту финального визита $(2,3 \pm 1,9 \text { года; } n=70)^{*}$

Table 5. Treatment with warfarin and DOACs after discharge from the hospital by the time of the final visit $(2,3 \pm 1,9 \text { years; } n=70)^{*}$

\begin{tabular}{|c|c|c|c|}
\hline AK & $\begin{array}{l}\text { Некорректный } \\
\text { прием, абс. (\%) }\end{array}$ & $\begin{array}{c}\text { Корректный } \\
\text { прием, абс. [\%] }\end{array}$ & $\begin{array}{l}\text { Значимость } \\
\text { различий } p\end{array}$ \\
\hline $\operatorname{ABK}(n=19)$ & $5(26,3)$ & $14(73,7)$ & \multirow[t]{2}{*}{0,944} \\
\hline ПОАК (n=51) & $13(25,5)$ & $38(74,5)$ & \\
\hline
\end{tabular}

*Исключены пациенты, умершие в ходе госпитализации, а также те пациенты, кто не выходил на контакт (не явился на визит и не участвовал в телефонных опросах) после госпитализации, а также те, кто не принимал AK.

При сравнении характера антикоагулянтной терапии, назначенной при выписке и используемой амбулаторно, можно сделать следующие выводы. Большинство пациентов продолжали придерживаться той терапии, которая назначена при выписке. Чаще всего пациенты прекращали прием АВК (18,5\% пациентов) по сравнению с ПОАК (10,7-0\%). Однако данные различия не достигли достоверной значимости $(p>0,05)$, вероятно, в связи с небольшим количеством наблюдений.

Доля пациентов, принимавших АК нерегулярно или использовавших некорректные дозы, значимо не отличалась среди тех, кому назначены ПОАК и АВК (табл. 5).

К моменту финального визита 7,3\% больных с ФП, перенесших ИМ, принимали совместно с АК 1 дезагрегант (АСК или клопидогрел), 2,9\% - ДААТ (АСК в комбинации с клопидогрелом). Дезагреганты назначались либо после перенесенного повторного острого коронарного события, либо после планового стентирования артерий, в том числе коронарных. Кроме того, 6 пациентов, прекративших прием АК, получали дезагреганты: в 3 случаях АСК 75-100 мг, в 3 - клопидогрел.

\section{Влияние АТт на отдаленный прогноз}

Первым этапом оценивался прогноз в течение 1 года после перенесенного ИМ. Сначала сравнивались 2 группы пациентов: те, кто не принимал АК после выписки или получал их в неправильных дозах, а также нерегулярно, и больные, принимавшие корректную двойную или тройную АТТ с АВК или ПОАК. Достоверных различий между этими группами не получено, возможно, по причине небольшого числа событий в течение 1 года после выписки (табл. 6).

Далее проведено сравнение двойной и тройной АТТ (суммарно как с АВК, так и с ПОАК в их составе, с исключением

Таблица 6. Однолетний прогноз в зависимости от приема АК

Table 6. One-year prognosis depending on treatment with anticoagulants (ACs)

\begin{tabular}{|l|c|c|}
\hline \multicolumn{1}{|c|}{$\begin{array}{c}\text { Внегоспитальное } \\
\text { событие }\end{array}$} & $\chi^{2}$ & $\begin{array}{c}\text { Значимость } \\
\text { различий } \boldsymbol{p}\end{array}$ \\
\hline Повторный ИМ & 0,0000 & 0,9966 \\
\hline Инсульт & 2,8188 & 0,0932 \\
\hline ТЭЛА & 0,8847 & 0,3469 \\
\hline $\begin{array}{l}\text { Большие } \\
\text { кровотечения }\end{array}$ & 0,0000 & 0,9982 \\
\hline Малые кровотечения & 0,0640 & 0,8004 \\
\hline $\begin{array}{l}\text { Сердечно-сосудистая } \\
\text { смертность }\end{array}$ & 0,1258 & 0,7228 \\
\hline Общая смертность & 0,0079 & 0,9292 \\
\hline ККТ & 0,6891 & 0,4065 \\
\hline
\end{tabular}


Таблица 7. Отдаленный прогноз за весь период наблюдения в зависимости от приема АK

Table 7. Long-term prognosis for the entire follow-up period depending on treatment with ACs

\begin{tabular}{|l|c|c|}
\hline \multicolumn{1}{|c|}{ Внегоспитальное событие } & $\chi^{2}$ & $\begin{array}{l}\text { Значимость } \\
\text { различий } \boldsymbol{p}\end{array}$ \\
\hline Повторный ИМ & 1,090 & 0,2965 \\
\hline Инсульт & 4,3753 & 0,0365 \\
\hline ТЭЛА & 1,0319 & 0,3097 \\
\hline Большие кровотечения & 0,1397 & 0,7085 \\
\hline Малые кровотечения & 0,5691 & 0,4506 \\
\hline Сердечно-сосудистая & 2,5031 & 0,1136 \\
\hline смертность & 0,5491 & 0,4587 \\
\hline Общая смертность & 4,8023 & 0,0284 \\
\hline
\end{tabular}

Таблица 8. Сравнение АВК и ПОАК по влиянию на внегоспитальные события за весь период наблюдения

Table 8. Comparison of VKA and DOACs by their effect on out-of-hospital events for the entire follow-up period

\begin{tabular}{|l|c|c|}
\hline Внегоспитальное событие & $\chi^{2}$ & $\begin{array}{c}\text { Значимость } \\
\text { различий } \boldsymbol{p}\end{array}$ \\
\hline Повторный ИМ & 0,1521 & 0,6965 \\
\hline Инсульт & 0,0000 & 0,9977 \\
\hline ТЭЛА & 0,2469 & 0,6193 \\
\hline Большие кровотечения & 0,0000 & 0,9985 \\
\hline Малье кровотечения & 0,0000 & 0,9949 \\
\hline $\begin{array}{l}\text { Сердечно-сосудистая } \\
\text { смертность }\end{array}$ & 0,7942 & 0,3728 \\
\hline Общая смертность & 0,7965 & 0,3804 \\
\hline ККТ & 1,2803 & 0,2578 \\
\hline
\end{tabular}

пациентов, принимавших АК неадекватно). Значимых различий по влиянию на 1-летний прогноз в зависимости от объема АТТ не получено ( $p>0,05$ для всех конечных точек).

Вторым этапом проведена оценка отдаленного прогноза за весь период наблюдения после выписки. При сравнении группы пациентов, не принимавших АК после выписки или получавших их в неправильных дозах, а также нерегулярно, и больных, принимавших АК адекватно, получены достоверные различия в наступлении сердечно-сосудистых событий (табл. 7).

При отсутствии в схемах лечения АК или их некорректном приеме значимо чаще происходили инсульты: отношение шансов - ОШ 9,580 (95\% доверительный интервал - ДИ 1,153-79,599), $p=0,0365$; встречалась ККТ - ОШ 2,556 (95\% ДИ 1,104-5,918), $p=0,0284$. Достоверных различий по влиянию данных схем на другие конечные точки не выявлено.

Далее (при исключении тех пациентов, кто принимал АК в некорректных дозах или нерегулярно) проведена оценка прогноза в группе пациентов, принимавших АВК и ПОАК. Достоверных различий по влиянию на отдаленный прогноз в зависимости от вида АК (АВК/ПОАК) не обнаружено (табл. 8).

\section{Обсуждение}

Проблема приверженности антикоагулянтной терапии в настоящее время широко обсуждается в литературе, как оте- чественной, так и зарубежной. Наиболее часто эти вопросы решаются применительно к рискам развития инсультов и других тромбоэмболических событий. Информации же о приверженности антикоагулянтной терапии и ее влиянии на прогноз у больных с ФП и ИМ значительно меньше [2, 6-8]. Так, по данным регистра острого коронарного синдрома по Краснодарскому краю [9] и ряда зарубежных исследований $[8,10]$, пациенты с ФП до госпитализации по поводу ИМ, получали АК редко: от 10,45 до $45,0-52,0 \%$ случаев соответственно, что согласуется с нашими результатами - 13,0\% случаев. Следует подчеркнуть, что по результатам настоящего исследования именно среди больных с ФП, либо не принимавших АК до госпитализации по поводу ИМ, либо получавших их некорректно, встречались те, кто умер в течение первых суток, а также те, у кого в 1-е сутки ИМ развивались тромбоэмболические события (ТЭЛА, инсульт).

По данным настоящего исследования, АК в стационаре назначены всем пациентам, при выписке - в 93,1\% случаев, в отличие от сведений литературы, согласно которым назначаемость АК у пациентов с ФП при выписке выше, чем до госпитализации в связи с ИМ, но оставалась на низком уровне - 35,0-77,0\% $[2,9,10]$. Большинство пациентов, по полученным нами данным, как в ходе стационарного лечения, так и в дальнейшем амбулаторно в качестве АК принимали ПОАК, что объясняется удобством их приема, а также безопасностью, и соответствует современным рекомендациям [11, 12].

ATТ у пациентов, по данным нашего исследования, оказалась многокомпонентной. Согласно действующим на тот момент (2013-2018 гг.) рекомендациям [4, 5], учитывая преобладание ишемических рисков над геморрагическими, пациентам чаще назначалась тройная терапия (77,9\% больных) как минимум в течение 1 мес с дальнейшим переходом на двойную с АК в ее составе, как правило, в течение 12 мес. В исследованиях последних лет, как российских, так и зарубежных, доля пациентов, получавших тройную АТТ при выписке, меньше $21,0-62,78 \%[9,10,13]$. Предпочтение отдавалось именно двойной терапии с АК по сравнению с тройной в связи с уменьшением риска кровотечений при ее неменьшей антитромботической эффективности [13-16]. Данные выводы нашли отражение и в последних рекомендациях по ФП $[11,12]$, согласно которым срок тройной терапии максимально сокращен, а также уменьшена продолжительность двойной терапии в группе пациентов с высокими рисками кровотечений.

В связи с большим числом больных, получавших «агрессивную» АТT, представляло интерес изучить частоту встречаемости у них кровотечений. По данным настоящего исследования, больших кровотечений, как в ходе стационарного лечения, так и в отдаленном периоде немного, в основном наблюдались малые, не требующие отмены терапии. Оказалось, что различий в частоте кровотечений в группе пациентов, получавших тройную АТT по сравнению с двойной не выявлено, также как и в исследовании 3.Г. Татаринцевой и соавт. [9]. Этот факт можно объяснить несколькими причинами. Во-первых, доза ПОАК в нашей выборке пациентов, согласно действующим на тот момент рекомендациям [4, 5], сниженная. Кроме того, всем пациентам в стационаре проведена профилактика кровотечений: назначены ингибиторы протонной помпы, большинству выполнены фиброгастродуоденоскопия, при наличии отягощенного анамнеза и изменений в анализе мочи - ультразвуковое исследование почек и мочевого пузыря.

По полученным нами данным, различий в частоте кровотечений в зависимости от типа АК (ПОАК или АВК) не отмечено. Достоверных отличий по встречаемости ишемических событий в зависимости от объема АТТ (двойная или тройная), типа АК (ПОАК или АВК) также не отмечено. Вероятнее всего, такое отсутствие 
различий в прогнозе можно объяснить тем, что схема терапии для каждого пациента подбиралась строго индивидуально в зависимости от соотношения рисков ишемических событий и кровотечений, а также осуществлялся контроль МНО при приеме АВК.

Обращал на себя внимание тот факт, что больные, получавшие парентеральные АК либо в комбинации с блокатором Р2Ү12, либо с ДААТ в ходе госпитализации, достоверно чаще умирали, и у них чаще развивалась ККТ. Однако анализ результатов обследования этой группы пациентов показал, что все они при поступлении имели осложненное течение ИМ (Killip 3-4), стволовое или многососудистое поражение коронарных артерий, поздние сроки госпитализации и пожилой или старческий возраст, поэтому, вероятнее всего, не характер терапии, а исходные характеристики пациентов в данном случае являются объяснением неблагоприятного прогноза. Все же следует подчеркнуть, что прием парентеральных АК должен заканчиваться после ЧКВ. При этом согласно последним рекомендациям АК, принимаемые до развития ИМ, не отменяются при ЧКВ [11, 12].

Число пациентов, продолжавших принимать АК после выписки, хоть и уменьшилось через 1 год (91,6\%) и к моменту финального визита $(84,3 \%)$, но осталось довольно высоким по сравнению с данными литературы, по-видимому, в связи с тем, что больные оставались под наблюдением исследователей. Вместе с тем приверженность антикоагулянтной терапии, т.е. регулярный прием АК в адекватных дозах, ниже: 82,0\%через год и 62,7\% - к моменту финального визита. Эти данные подчеркивают необходимость постоянного контроля со стороны врачей за режимом приема АК. По сведениям литературы, среди больных с ФП, перенесших ИМ, доля пациентов, получавших АК (без учета адекватности приема), через 6-12 мес снижалась до 52,3\% [9]. По результатам настоящего исследования, именно отмена АК, а также их некорректный прием связаны с увеличением частоты инсульта, и ККТ (повторный ИМ + инсульт + сердечно-сосудистая смертность) в отдаленном периоде. Это согласуется с результатами других исследований, согласно которым отсутствие адекватной антикоагулянтной терапии у больных с ФП, перенесших ИМ, ассоциировано с повышением смертности, частоты инсультов $[2,10]$.

\section{Заключение}

Пациенты с ФП крайне редко принимают АК в период до госпитализации по поводу ИМ. После выписки из стационара приверженность приему АК возрастает, но затем вновь снижается. Вид АК (АВК или ПОАК) и объем АТТ (двойная или тройная) при назначении в соответствии с ишемическими и геморрагическими рисками, а также постоянном наблюдении за пациентами не сказались на прогнозе. Вместе с тем некорректный прием АК или их отмена у пациентов с ФП, перенесших ИМ, достоверно влияют на отдаленный прогноз, повышая риски инсульта и ККТ (повторный ИМ + инсульт + сердечнососудистая смертность).

Таким образом, проблема низкой приверженности АК по-прежнему является чрезвычайно актуальной и заслуживает особого внимания. Больные с ФП, перенесшие ИМ, являются группой наиболее высокого риска, требующей более тщательного наблюдения, более частых врачебных осмотров после ИМ.

Конфликт интересов. Авторы заявляют об отсутствии конфликта интересов.

Conflict of interests. The authors declare no conflict of interest.

Вклад авторов. Все авторы подтверждают соответствие своего авторства, согласно международным критериям ICMJE.

Соловьева М.В. - сбор материала, статистическая обработка результатов, обзор литературы, написание текста статьи;

Болдуева С.А. - научное руководство, обобщение полученных результатов, редактирование текста статьи.

Authors' contribution. All authors confirm the compliance of their authorship according to the international ICMJE criteria.

Mariia V. Soloveva - collecting data, statistical processing of the data,literature review, writing the text of the manuscript;

Svetlana A. Boldueva - academic advising, generalization of the data obtained editorial correction of the text of the manuscript.

Источник финансирования. Бюджетное финансирование, плановая научно-исследовательская и публикационная деятельность СЗГМУ им. И.И. Мечникова.

Funding source. Budget funding, planned research and publication activities of Mechnikov North-Western State Medical University.

\section{Информация об авторах / Information about the authors}

\begin{abstract}
Соловьева Мария Владимировна - врач-кардиолог отд-ния рентгенхирургических методов диагностики и лечения ФГБОУ ВО «СЗГМУ им. И.И. Мечникова», аспирант каф. факультетской терапии ФГБОУ ВО «СЗГМУ им. И.И. Мечникова». Е-mail: morethantea@rambler.ru;

ORCID: 0000-0002-3335-4986
\end{abstract}

Болдуева Светлана Афанасьевна - д-р мед. наук, проф., зав. каф. факультетской терапии ФГБОУ ВО «СЗГМУ им. И.И. Мечникова».

ORCID: 0000-0002-1898-084X $\square$ Mariia V. Soloveva - Graduate Student, Mechnikov North-Western State Medical University. E-mail: morethantea@rambler.ru; ORCID: 0000-0002-3335-4986

Svetlana A. Boldueva - D. Sci. (Med.), Prof., Mechnikov North-Western State Medical University. ORCID: 0000-0002-1898-084X

\section{Литература/References}

1. Болдуева С.А., Соловьева М.В., Облавацкий Д.В., и др. Инфаркт миокарда у больных с фибрилляцией предсердий. Кардиология. 2020;60(1):53-61 [Boldueva SA, Soloveva MV, Oblavatckii DV, et al. Myocardial infarction in the group of patients with atrial fibrillation. Kardiologiia. 2020;60(1):53-61 (in Russian)]. D01:10.18087/cardio.20201.n620

2. Soliman $E Z$, Safford $M M$, Muntner $P_{1}$, et al. Atrial fibrillation and the risk of myocardial infarction. JAMA Intern Med. 2013;174(1):107-14. D0I:10.1001/jamainternmed.2013.11912

3. Lopes RD, Pieper KS, Horton JR, et al. Short- and long-term outcomes following atrial fibrillation in patients with acute coronary syndromes with or without ST-segment elevation. Heart. 2008;94:867-73. D0l:10.1136/hrt.2007.134486
4. Roffi M, Patrono C, Collet JP, et al. 2015 ESC Guidelines for the management of acute coronary syndromes in patients presenting without persistent ST-segment elevation. Eur Heart J. 2016;37:267-315. DOI:10.1093/eurheartj/ehv320

5. Ibanez B, James S, Agewall $\mathrm{S}$, et al. 2017 ESC guidelines for the management of acute myocardial infarction in patients presenting with ST-segment elevation. Eur Heart J. 2018;39(38):119-77. D0l:10.1093/eurheartj/ehx393

6. Lip GY, Lane DA. Does warfarin for stroke thromboprophylaxis protect against MI in atrial fibrillation patients? Am J Med. 2010;123(9):785-9. D0l:10.1016/j.amjmed.2010.01.031

7. Беленков Ю.Н., Шакарьянц Г.А., Хабарова Н.В. Тактика подбора антикоагулянтной терапии у пациентов с фибрилляцией предсердий 
и ишемической болезнью сердца. Кардиология. 2018;58(3):43-52 [Belenkov YuN, Shakaryants GA, Khabarova NV. Tactics of Selection of Anticoagulant Therapy in Patients With Atrial Fibrillation and Ischemic Heart Disease. Kardiologiia. 2018;58(3):43-52 (in Russian)]. DOI:10.18087/cardio.2018.3.10098

8. Lee CJY, Pallisgaard JL, Bjerring J0, et al. Antithrombotic Therapy and First Myocardial Infarction in Patients With Atrial Fibrillation. J Am Coll Cardiol. 2017;69(24):2901-9. D0l:10.1016/j.jacc.2017.04.033

9. Татаринцева З.Г., Космачева Е.Д., Кручинова С.В., и др. Антитромбоцитарная терапия у пациентов с фибрилляцией предсердий на фоне острого коронарного синдрома в реальной клинической практике (по данным тотального регистра острого коронарного синдрома по Краснодарскому краю). Кардиология: новости, мнения, обучение. 2018;6(4):6-13 [Tatarintseva ZG, Kosmacheva ED, Kruchinova SV, et al. Antiplatelet therapy in patients with atrial fibrillation on the background of acute coronary syndrome in real clinical practice according to the total register of acute coronary syndrome in the Krasnodar Territory. Cardiology: News, Opinions, Training. 2018;6(4):6-13 (in Russian)]. D0I:10.24411/2309-1908-2018-14001

10. Jortveit J, Pripp AH, Langørgen J, Halvorsen S. Poor adherence to guideline recommendations among patients with atrial fibrillation and acute myocardial infarction. Eur J Prev Cardiol. 2019;26(13):1373-82. DOI:10.1177/2047487319841940

11. Collet JP, Thiele H, Barbato E, et al.2020 ESC Guidelines for the management of acute coronary syndromes in patients presenting without persistent ST-segment elevation: The Task Force for the management of acute coronary syndromes in patients presenting without persistent STsegment elevation of the European Society of Cardiology (ESC). Eur Heart J. 2020;ehaa575. D0l:10.1093/eurheartj/ehaa575

12. Hindricks G, Potpara $T$, Dagres N, et al. 2020 ESC Guidelines for the diagnosis and management of atrial fibrillation developed in collaboration with the European Association for Cardio-Thoracic Surgery (EACTS): The Task Force for the diagnosis and management of atrial fibrillation of the European Society of Cardiology (ESC) Developed with the special contribution of the European Heart Rhythm Association (EHRA) of the ESC. Eur Heart J. 2021;42(5):373-498. D0l:10.1093/eurheartj/ehaa612

13. Hess $C N$, Peterson ED, Peng $S A$, et al. Use and outcomes of triple therapy among older patients with acute myocardial infarction and atrial fibrillation. J Am Coll Cardiol. 2015;66(6):616-27. D0l:101016/j.jacc.2015.05.062

14. Lopes RD, Hong H, Harskamp RE, et al. Optimal antithrombotic regimens for patients with atrial fibrillation undergoing percutaneous coronary intervention: an updated network meta-analysis. JAMA Cardiol. 2020;5(5):582-9. D0l:10.1001/jamacardio.2019.6175

15. Batra G, Friberg L, Erlinge D, et al. Antithrombotic therapy after myocardial infarction in patients with atrial fibrillation undergoing percutaneous coronary intervention. Eur Heart $\mathrm{J}$ Cardiovasc Pharmacother. 2018;4(1):36-45. D0I:10.1093/ehjcvp/pvx033

16. Lamberts $M$, Gislason $\mathrm{GH}$, Olesen JB, et al. Oral anticoagulation and antiplatelets in atrial fibrillation patients after myocardial infarction and coronary intervention. J Am Coll Cardiol. 2013;62:981-9. D01:10.1016/j.jacc.2013.05.029 